\title{
Associative Diversity of ITS 1 gene in Different Trypanosoma evansi Isolates of Equine Origin from Semi Arid India
}

\author{
Ruchi Singh Gaur ${ }^{1 *}$, Daya Shanker ${ }^{1}$, Vikrant Sudan ${ }^{1}$, Shanker Singh ${ }^{2}$ and Ashutosh Jadaun ${ }^{3}$ \\ ${ }^{1}$ Department of Parasitology, College of Veterinary Science and Animal Husbandry, DUVASU, Mathura, INDIA \\ ${ }^{2}$ Department of Veterinary Clinical Medicine, College of Veterinary Science and Animal Husbandry, DUVASU, Mathura, INDIA \\ ${ }^{3}$ Veterinary Officer, Dharapura, Dholpur, Rajasthan, INDIA \\ *Corresponding author: RS Gaur; E-mail: ruchigaur2050@gmail.com
}

Received: 02 June, 2021

Revised: 08 July, 2021

Accepted: 12 July, 2021

\begin{abstract}
Trypanosoma evansi is an important haemoprotozoan parasite from the Indian context. A wide range of variations in the parasite genotype and subsequently, in disease pathogenesis have been described in the literature. The present study was designed to find out the associative genetic diversity, within the various equine isolates of $T$. evansi across India and the globe, based on the ITS 1 gene. A total of five equine isolates were characterized. PCR products were sequenced. A phylogenetic tree was constructed based on the maximum parsimony (MP) method with the tree-bisection-regrafting (TBR) algorithm. Indian isolates formed three haplotypes. The present isolates showed $99.06-100.00 \%$ nucleotide homology within themselves. In broader terms, present isolates were found to be phylogenetically closer isolates from Haryana. Broadly, Indian isolates of $T$. evansi were closely related to isolates reported from Thailand and China than those from Iran, Nigeria, and Egypt. Another remarkable finding is the close association of equine isolates from India with other isolates of family equidae and their clear divergence from isolates of $T$. evansi affecting other hosts from India and abroad. Vast genetic divergence was seen between the isolates suggesting of multiple distinct lineages of $T$. evansi amongst the Indian livestock.
\end{abstract}

\section{HIGHLIGHTS}

(0 Study comprised of characterization of equine isolates of Trypanosoma evansi from semi arid India based on ITS gene.

0 Appreciable genetic diversity was noticed based on ITS gene locus.

(0 Marked host specific closeness was noticed between equine isolates on the phylogenetic tree.

Keywords: Phylogenetic characterization, ITS 1 gene, Trypanosoma evansi

Trypanosoma evansi infects a wide range of domestic animals alongside wild life and causes the disease- Surra (Sudan et al., 2017a). The haemoflagellate parasite is a serious threat to the optimum health and productivity of animals throughout the world (Desquesnes et al., 2013; Jaiswal et al., 2015; Pandey et al., 2015). There are ample reports of existence of genetic diversity within the various isolates of $T$. evansi across the globe (Desquesnes et al., 2013). A large number of target molecules have been explored to assess the phenotypic characterization $T$. evansi like 18S rRNA (Hughes and Piontkivska, 2003), ITS 1 (Villareal et al., 2013), oligopeptidase B (Sudan et al., 2018), variable surface glycoprotein (VSG) (Devi et al., 2017a; 2018; Sudan et al., 2017b), heat shock protein (HSP 70) (Sudan et al., 2017c), beta-tubulin (Li et al., 2007) and actin (Li et al., 2009) genes.

The present study was designed with the objective of characterization of five equine isolates of $T$. evansi based on ITS gene. Alongside, the evolutionary phylogenetics of various isolates of T. evansi, affecting different host species

How to cite this article: Gaur, R.S., Shanker, D., Sudan, V., Singh, S and Jadaun, A. (2021). Associative Diversity of ITS 1 gene in Differen Trypanosoma evansi Isolates of Equine Origin from Semi Arid India. J. Anim. Res., 11(04): 755-760.

Source of Support: None; Conflict of Interest: None 
across the world, was also delineated. Finally, nucleotide homology within these isolates was comminuted.

\section{MATERIALS AND METHODS}

Topography, T. evansi isolates, ethical compliance and DNA extraction

The studied area is located at $27.49^{\circ} \mathrm{N}$ latitude and $77.67^{\circ} \mathrm{E}$ longitude axis, respectively, in semi-arid zone of India. The area is considered to be endemic for haemoprotozoan diseases due to warm temperature and high humidity with a little of rainfall in the area that favours the abundance of vector population (Patel et al., 2013).

The blood was collected in compliance with the ethical standards of the Institutional Animal Ethics Committee (IAEC) via., voucher no. $125 / \mathrm{IAEC} / 19 / 12$ dated $22^{\text {th }}$ January, 2019. Blood samples were collected from equines as a part of routine epidemiological survey for surra. A total of five samples that were found positive for T. evansi infection [through microscopic examination and confirmation by PCR (Devi et al., 2017b) were processed for DNA extraction using commercial blood DNA isolation kit (Fermentas, Germany) following manufacturer's protocol.

\section{Primer selection, PCR conditions and visualization of PCR amplification}

The primers specific for ITS 1 gene of T. evansi (Mc Laughlin et al., 1996) were custom synthesized from Imperial Life Sciences Pvt. Ltd., Gurugram, India. The primer sequences consisted of ITS1-F: 5/-CGCCCGAAAGTTCACC-3/' and ITS1-R: 5'-GCGTTCAAAGATTGGGCAAT-3'. These primers encoded for a $540 \mathrm{bp}$ product. The PCR reaction were set up into $50 \mu \mathrm{l}$ volume containing $25 \mu \mathrm{l}$ of Green PCR Master Mix (0.05/ $\mu$ TTaq DNA polymerase in reaction buffer, $4 \mathrm{mM} \mathrm{MgCl}_{2}, 0.4 \mathrm{mM}$ dATP, $0.4 \mathrm{mM} \mathrm{dCTP}, 0.4$ $\mathrm{mM}$ dGTP, and $0.4 \mathrm{mM}$ dTTP), $3 \mu \mathrm{l}$ of each primer (10 $\mathrm{pmol} / \mu \mathrm{l}$ of each primer) and $5 \mu \mathrm{l}$ of the extracted DNA template. The total volume of the PCR mix was made up to $50 \mu \mathrm{l}$ using nuclease-free water. The PCR conditions consisted of initial denaturation at $94^{\circ} \mathrm{C}$ for $5 \mathrm{~min}$ followed by 35 cycles of denaturation at $94^{\circ} \mathrm{C}$ for $40 \mathrm{sec}$, annealing at $58{ }^{\circ} \mathrm{C}$ for $40 \mathrm{sec}$ and extension at $72{ }^{\circ} \mathrm{C}$ for $90 \mathrm{sec}$. A final extension at $72{ }^{\circ} \mathrm{C}$ for $5 \mathrm{~min}$ was given before termination. The amplified products were visualized in ethidium bromide incorporated $1.5 \%$ agarose gel.
Sequencing, sequence analysis and construction of phylogenetic tree

The PCR products were purified using Gel purification and DNA clean up kit (Promega, USA) following the manufacturer's protocol and sent for outsourced DNA sequencing (both forward and reverse sides) to Invitrogen Bio Sciences Pvt. Ltd., Gurugram, India. The obtained sequences were submitted into NCBI and corresponding accession numbers were obtained. A multiple sequence alignment was generated with the Clustal W programme within MEGA 6 software (Tamura et al., 2011) using both the pair-wise and multiple alignments. The phylogenetic relationship was constructed employing maximum parsimony (MP) method with the tree-bisectionregrafting (TBR) algorithm. The sequences were truncated at both ends, so that nearly all sequences started and ended at the homologous nucleotide position. The phylogeny was tested with bootstrap method using 1000 bootstrap replications and all sites were used in the analysis. Alongside, nucleotide homology between the sequences was also calculated.

\section{RESULTS AND DISCUSSION}

\section{PCR amplification of ITS 1 gene}

A single band of $540 \mathrm{bp}$ was seen upon agarose gel electrophoresis in all the five equine isolates of T. evansi (Fig. 1).

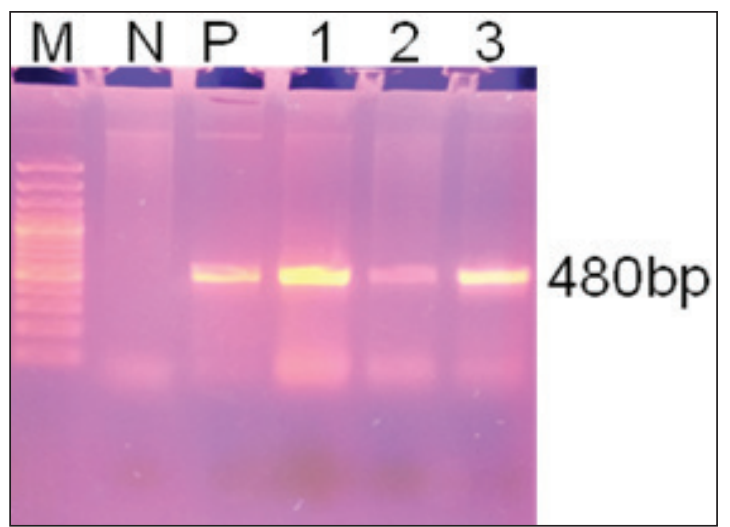

Lane M: 100bp plus ladder (Fermentas, Germany); Lane N: Known negative control; Lane P: Known positive control (DNA of $T$. evansi); Lane1-3: Equine isolates of T. evansi (480 bp amplification)

Fig. 1: PCR based amplification of ITS 1 gene of T. evansi 


\section{Sequence and phylogenetic analysis}

The five sequences were submitted to NCBI and accession numbers (MT605803- MT605807) were obtained. The phylogenetic analysis revealed three haplotypes with multiple nucleotide changes (Fig. 2). Sequences MT605803-05 represented one haplotype while sequences MT605804 and MT605805 represented two separate haplotypes (Fig. 3). In general, the present sequences showed 99.06-100.00\% nucleotide homology within themselves wherein the sequences in the first haplotype (MT605803-05) showed 100\% nucleotide
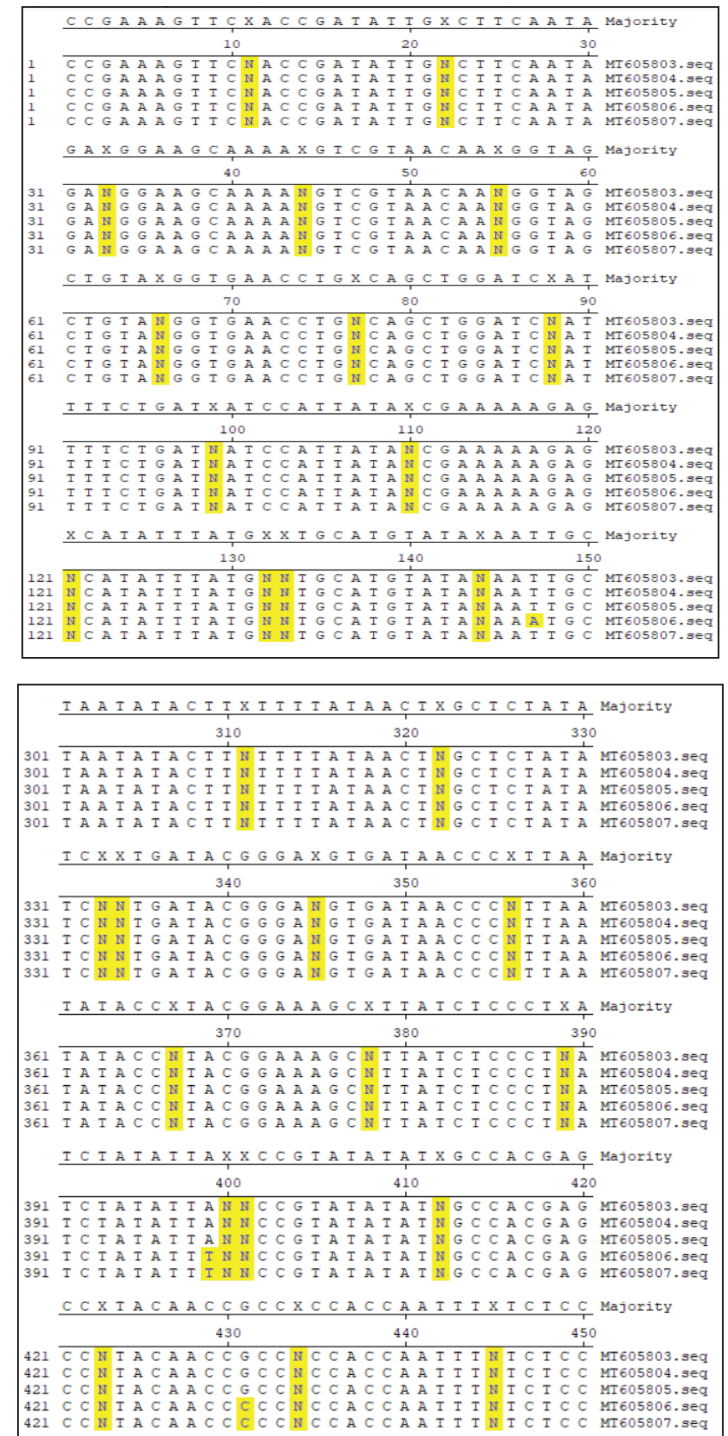

homology within themselves while they showed 99.06 and $99.25 \%$ nucleotide homologies with the rest two haplotypes (MT605804 and MT605805, respectively). On broader terms, all the five equine isolates were found to be phylogenitically closer to the pony isolate from Haryana, India. Wide variation was noticed among the various Indian isolates and overall the Indian isolates were found scattered all over the phylogenetic tree (Fig. 3 ) with variable similarities to respective $T$. evansi isolates reported worldwide. Broadly, Indian isolates of $T$. evansi were closely related to isolates reported from Thailand and China than those from Iran, Nigeria and Egypt.
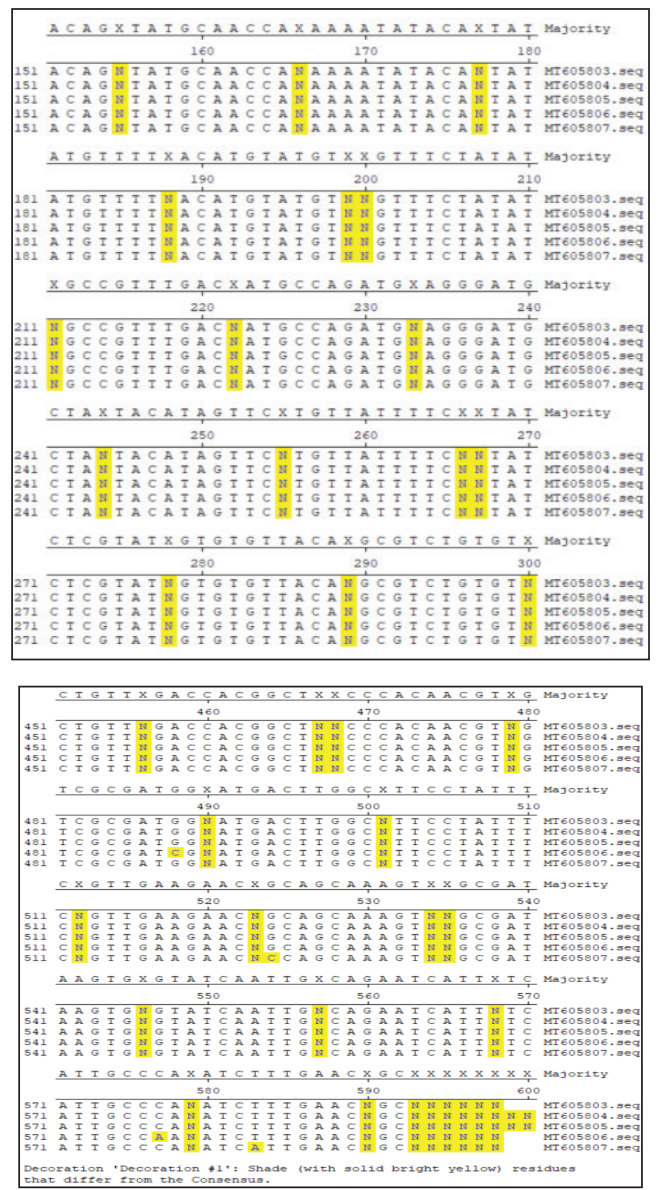

Fig. 2: Nucleotide changes observed in the various isolates of $T$. evansi based on ITS 1 gene (changes are depicted by yellow colour) 


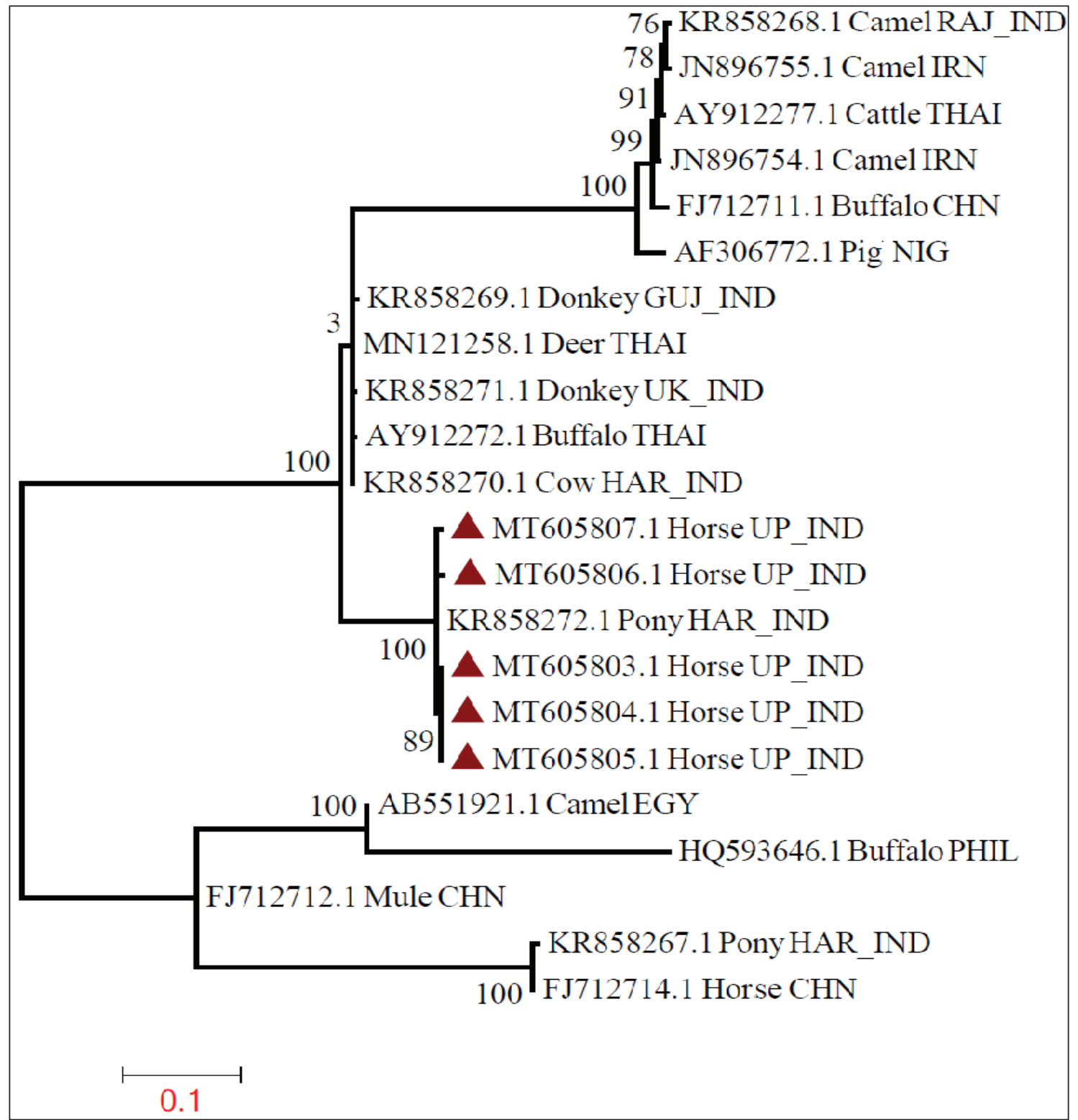

Fig. 3: Phylogenetic relationship of T. evansi isolates across the world based ITS 1 gene. All accession numbers corresponds to different $T$. evansi isolates followed by their country of origin and the host from which it was isolated. The sequences generated in the present study are marked as red triangle. \{CHN: China; NIG: Nigeria; PHIL: Philippines; THAI: Thailand; IRN: Iran; IND: India (GUJ: Gujarat; HAR: Haryana; RAJ: Rajasthan; UP: Uttar Pradesh)\}

The ribosomal DNA (rDNA) genes have been very much significant in molecular and phylogenetic analysis of trypanosomes alongside their taxonomic identity. The present communication aimed at phylogenetic characterization of equine isolates of T. evansi from semi arid India based on ITS1 region of rDNA gene. In the present study, the various stocks of $T$. evansi affecting different hosts, across different countries, were phylogenetically compared on ITS 1 locus. Characterization of five equine $T$. evansi isolates showed distribution into three haplotypes with 99.06-100.00\% nucleotide homology within themselves. In comparison with the isolates across the globe, they were phylogenetically closer to $T$. evansi isolates reported from Haryana than to the isolates 
reported from rest of India. So far as global scenario is concerned, the Indian isolates of $T$. evansi were closely related to isolates from Thailand and China than to those reported from Iran, Nigeria and Egypt. Wide distribution of Indian isolates on the phylogenetic tree and their marked resemblance with specific yet selective isolates across the globe have raised questions about presence of multiple distinct lineages of T. evansi amongst the Indian livestock.

Sarkhel et al. (2017) reported genetic variability in T. evansi isolates, from different regions of India and affecting different hosts, based on ITS 1 gene. However, Areetik et al. (2008), in their preliminary work, described ITS 1 region as an unsuitable marker for analyzing genetic diversity within a clonal population of $T$. evansi originating from a single host. This was attributed to the robustness of the phylogenetic tree based on ITS 1 gene that suffers from lower bootstrap values indicating a higher feasibility of tree collapse (Tian et al., 2011). Selection of a comparatively larger nucleotide sequence length often helps to nullify such scenario (Sarkhel et al., 2017). Another remarkable finding in the present study is the close association of equine isolates from India with other isolates of $T$. evansi affecting members of family equidae as their hosts (pony, mule and donkey) and their clear divergence from isolates of $T$. evansi affecting other hosts (buffalo, cattle, deer, camel and pig). Although, this is a very preliminary observation yet the fact cannot be nullified that isolates of T. evansi have got markedly closeness among the related hosts. Similar genetic heterogeneity among $T$. evansi isolates derived from different hosts has earlier been also reported using APPCR (Kundu et al., 2010) alongside, using RoTat 1.2 VSG (Gaur et al., 2021) and ITS 1(Sarkhel et al., 2017) genes in sequence based studies.

\section{CONCLUSION}

The findings of the present study are very much significant from molecular evolutionary point of view. Well planned studies using different molecular targets and covering a large number of isolates of $T$. evansi affecting different hosts need to be done for actual delineation of evolutionary phylogenetics. Moreover, the effect of host species and phylogenetics of distribution of $T$. evansi needs to be thoroughly analyzed.

\section{ACKNOWLEDGEMENTS}

The authors are highly thankful to the Director Research, Dean CoVSc and Vice Chancellor, DUVASU, for the facilities provided. The authors also want to acknowledge the various funding agencies like Indian Council of Agricultural Research (ICAR) and Rashtriya Krishi Vikas Yojana (RKVY) for sanctioning various projects to the University.

\section{REFERENCES}

Areekit, S., Singhaphan, P., Kanjanavas, P., Khuchareontaworn, S., Sriyapai, T., Pakpitcharoen, A. and Chansiri K. 2008. Genetic diversity of Trypanosoma evansi in beef cattle based on internal transcribed spacer region. Inf. Genetics Evol., 8: $484-488$.

Desquesnes, M., Holzmuller, P., Lai, D.H., Dargantes, A., Lun, Z.R. and Jittaplapong S. 2013. Trypanosoma evansi and Surra: A review and perspectives on origin, history, distribution, taxonomy, morphology, hosts and pathogenic effects. BioMed. Res. Int., 194176.

Devi, A., Shanker, D., Sudan, V., Jaiswal, A.K. and Singh, A. 2017a. Molecular characterization and phylogenetic sequence analysis of unique conserved portion of VSG of Trypanosoma evansi. Indian J. Anim. Sci., 87(8): 974-976.

Devi, A., Shanker, D., Sudan, V. and Chaudhaury M. 2017 b. PCR-based diagnosis of surra in equines targeting RoTat 1.2 VSG gene. J. Vet. Parasitol., 31(2):74-78.

Devi, A., Shanker, D., Sudan, V., Jaiswal, A.K. Singh A. and Chaudhaury, M. 2018. Phylogenetic studies on RoTat 1.2 VSG of Trypanosoma evansi isolate from semi arid India. Indian J. Anim. Sci., 88(2):150-152.

Gaur, R., Shanker, D., Sudan, V., Paliwal, S., Singh, S.K. and Jadaun, A. 2021. Associative genetic diversity of RoTat 1.2 VSG in different Trypanosoma evansi isolates. Acta Parasitol., 66: 199-204.

Hughes, A.L. and Piontkivska, H. 2003. Molecular phylogenetics of Trypanosomatidae: contrasting results from 18S rRNA and protein phylogenies. Kinetoplastida Bio. Dis., 2(1): 15.

Jaiswal , A., Sudan, V., Neha and Verma, A.K. 2015. Insight into Trypanosomiasis in Animals: Various Approaches for its Diagnosis, Treatment and Control: A Review. Asian J. Anim. Sci., 9(5): 172-186.

Kundu, K., Rao, J.R., Tewari, A.K., Baidya, S. and Mishra, A.K. 2010. Existence of genetic variability among Indian isolates of Trypanosoma evansi. Indian J. Anim. Sci., 80: 3-6.

Li, S.Q., Fung, M.C., Reid, S.A., Inoue, N. and Lun, Z.R. 2007. Immunization with recombinant beta-tubulin from 
Trypanosoma evansi induced protein T. evansi, T. equiperdum and T.b. brucei infection in mice. Parasit. Immunol., 29: 191-199.

Li, S.Q., Yang, W.B., Lun, Z.R., Ma, L.J., Xi, S.M., Chen, Q.L., Song, X.W., Kang, J. and Yang, L.Z. 2009. Immunization with recombinant actin from Trypanosoma evansi induces protective immunity against T. evansi, T. equiperdum and T.b. brucei infection. Parasitol. Res. 104: 429-435.

Mc Laughlin, G.L., Ssenyonga, S.S., Nanteza, E., RubaireAkiki, W.O., Hansen, R.D., Vodkin, M.H., Novak, R.J., Gordon, V.R., Montenegro- James, S., James, M., Armijos, R., Santrichm, C., Weigle, K., Santrich, C., Saravia, N., Wozniak, E., Gaye, O., Mdachi, R., Shapiro, S.Z., Chang, K.P., Santrich, C. and Kakoma, I. 1996. PCR based detection and typing of parasites. In: Zcel MA, Alkan MZ (eds) Parasitology for the $20^{\text {th }}$ century. CAB International, Wallingford, pp. 261-87.

Pandey ,V., Nigam, R., Jiaswal, A.K., Sudan, V., Singh, R.K. and Yadav, P.K. 2015. Haemato biochemical and oxidative status of buffaloes naturally infected with Trypanosoma evansi. Vet. Parasitol., 212: 118-222.

Patel, G., Shanker, D., Jaiswal, A.K., Sudan, V. and Verma, S.K. 2013. Prevalence and seasonal variation in ixodid ticks on cattle of Mathura district, Uttar Pradesh. J. Parasit. Dis., 37(2): 173-176.

Sarkhel, S.P., Gupta, S.K., Kaushik, J., Singh, J., Gaur, D.K., Kumar, S. and Kumar, R.2017. Molecular characterization of internal transcribed spacer 1 (ITS 1) region of different Trypanosoma evansi isolates of India. J. Parasit. Dis., 41(2): 527-533.
Sudan, V., Jaiswal, A.K. and Verma, A.K. 2017a. Trypanosomosis of wild animals with emphasis on Indian scenario. Veterinnary Parasitolology: Regional Studies and Reports, 10: 25-28.

Sudan, V., Jaiswal, A.K., Shanker, D. and Verma, A.K. 2017b. First report of molecular characterization and phylogenetic analysis of RoTat 1.2 VSG of Trypanosoma evansi from equine isolate. Trop. Anim. Heal., Prod., 49(8): 1793-1796.

Sudan, V., Shanker, D., Jaiswal, A. K., Singh, A. and Parashar, R. 2017c. Molecular characterization of serine oligopeptidase B gene of Trypanosoma evansi equine isolate from semi-arid India and its phylogenetic analysis with other trypanosomatids. J. Vet. Parasitol., 31(1): 30-36.

Sudan, V., Jaiswal, A.K. and Shanker, D. 2018. Heat shock protein 70 of Trypanosoma evansi is phylogenitically closer to salivaria than stercoraria homologs. Comp. Clin. Pathol., 27: $245-248$.

Tamura, K., Peterson, D., Peterson, N., Stecher, G., Nei, M and Kumar, S. 2011. MEGA5: molecular evolutionary genetics analysis using maximum likelihood, evolutionary distance, and maximum parsimony methods. Mol. Biol. Evol., 28:2731-2739.

Tian, Z., Liu, G., Xie, J., Shen, H., Zhang, L., Zhang, P. and Luo, J. 2011. The internal transcribed spacer 1 (ITS-1), a controversial marker for the genetic diversity of Trypanosoma evansi. Exp. Parasitol., 129: 303-306.

Villareal, M.V., Mingala, C.N. and Rivera, W.L. 2013. Molecular characterization of Trypanosoma evansi isolates from water buffaloes (Bubalus bubalis) in the Philippines. Acta Parasitol., 58: 6-12. 